\title{
Empirical Investigation of Retail Expansion and Cannibalization in a Dynamic Environment
}

\author{
Joseph Pancras \\ School of Business, University of Connecticut, Storrs, Connecticut 06269, jpancras@business.uconn.edu \\ S. Sriram \\ Ross School of Business, University of Michigan, Ann Arbor, Michigan 48109, ssrira@umich.edu \\ V. Kumar \\ J. Mack Robinson College of Business, Georgia State University, Atlanta, Georgia 30302, vk@gsu.edu
}

\begin{abstract}
$\mathrm{M}$ anagers of retail chains who seek to add new stores or close existing ones need to know the net impact of a store's opening/closure on the overall chain performance. This requires inferring the extent to which each store generates incremental sales as opposed to competing with other stores belonging to the chain for the same set of customers. However, when the chain is experiencing a growth or a decline in sales, not accounting for these dynamics in goodwill is likely to yield misleading estimates of incremental sales versus cannibalization. Moreover, firms might have been strategic in opening outlets in locations with favorable characteristics. We need to control for this location endogeneity while inferring the marginal effect of store opening/closure. In this paper, we develop a demand model that accounts for dynamics in goodwill, location endogeneity, and spatial competition between geographically proximate retail outlets. We calibrate the model parameters on both attitudinal and behavioral data for a fast food chain in a large U.S. city. The results imply that consumers perceive a travel cost of $\$ 0.60$ per mile. As regards the composition of sales at individual stores, on average, $86.7 \%$ of sales constitute incremental purchases with the rest derived from cannibalized sales from nearby stores belonging to the chain. We also find significant decay in cannibalization with distance such that when the distance between stores increases by one mile, the sales lost due to cannibalization decreases by $28.1 \%$; there is virtually no cannibalization at a distance of 10 miles. In terms of managerial applications, we discuss how managers can use the model presented in this paper to make two key decisions: (a) isolating locations that can be closed by identifying stores that yield the lowest marginal benefit to the chain and (b) dealing with franchisees' potential concerns about cannibalization.
\end{abstract}

Key words: marketing; retailing and wholesaling; advertising and media; economics; econometrics

History: Received July 2, 2010; accepted January 20, 2012, by Preyas Desai, marketing. Published online in

Articles in Advance June 5, 2012.

\section{Introduction}

Managers of retail chains face constant pressure to increase their sales and market share. Given that the geographic reach of any one retail store is necessarily limited (Kumar and Leone 1988), many managers often resort to the strategy of opening new outlets to meet this objective. However, the impact of new store openings on chain sales and profitability can be complex, especially in a dynamic context. For example, if new stores are opened in close proximity to existing stores belonging to the chain, they would vie for the same set of customers. The resulting cannibalization could have an adverse effect on the profitability of existing stores. However, this adverse effect can be attenuated by overall growth in the chain's performance. A case in point is the recent performance of Starbucks, a chain that experienced growth by opening new stores at a fast pace (Kiviat 2008). However, recent evidence suggests that these new stores failed to generate much additional sales and ended up cannibalizing from nearby stores, especially when the chain experienced a decline during the recession (Kiviat 2008, Quelch 2008).

The Starbucks example highlights that to evaluate the profit impact of opening or closing outlets, managers need answers to the following questions: (a) What is the marginal effect increase (or decrease) in the overall chain sales due to the opening (or closure) of a store after accounting of the redistribution of sales among other stores in the neighborhood? (b) What would be the effect of opening or closure on individual stores in the neighborhood (i.e., what fraction of their sales would existing stores lose (gain) when the store opens (closes))? (c) What growth in chain sales would leave the sales at incumbent stores unaffected by entry? In a franchising context, these questions are likely to be of interest to both the franchisor and individual franchisees (Kaufmann and 
Rangan 1990). Especially, in instances where incumbent franchisees perceive a threat from the opening of a new outlet in their vicinity, the franchisor needs to assure them that sufficient demand potential exists in the market to accommodate the new entrant. This can be accomplished by signaling the attractiveness of the market via appropriate choice of fee structures (Desai and Srinivasan 1995) or by using data to demonstrate that the adverse effect of cannibalization is limited. Our research is in the spirit of the second approach.

To infer the effect of a new store opening, the data need to have three characteristics: (a) presence of multiple geographically dispersed outlets, (b) opening and/or closing of a few outlets over time, and (c) sales data at each of the outlets over time. Furthermore, to control for changes in competitive environment, we need information on the configuration of outlets belonging to competing chains over time. As Singh and Zhu (2008) note, such data are hard to come by and are seldom publicly available. As a result, whereas researchers have considered the effects of opening a new store using simulated data, surveys, and conjoint studies (see, for example, Ghosh and Craig 1986), there has been little empirical documentation using real sales data. The objective of this study is to understand the effect of opening a new store (especially, the three questions raised above) using sales data from a chain of fast food restaurants. As we discuss subsequently, our data have all the three characteristics discussed above and enable us to empirically evaluate the extent of cannibalization versus incremental sales.

If one had access to panel data with the characteristics described above, a simple approach to measure incremental sales would involve comparing the overall chain sales before and after the new store was opened. Likewise, we can infer the cannibalization at incumbent stores by considering the decrease in sales after entry. However, there are at least four factors that need to be considered before embarking on such an approach. First, if the chain were experiencing an overall growth in its performance, it might realize a positive growth in sales in all its locations, including the ones located close to the new store. In such a context, by ignoring these dynamics, one might erroneously infer little or no cannibalization. Second, if the chain opens multiple stores within close proximity, we cannot infer the marginal effect of opening each store based on a simple before-after comparison of sales. Third, the presence of geographically dispersed outlets (albeit within the metropolitan area) implies that we need to consider the configuration of stores vis-à-vis the captive market while inferring cannibalization. Specifically, the demand for a store would depend upon the size of its captive market (i.e., its distance from population centers) as well as the extent of competition from stores belonging to own and competing chains. Furthermore, stores that are located closer to the new store are likely to be more adversely affected by the opening compared to stores located farther away (Huff 1964, Huff and Batsell 1977). In such a context, the inference of cannibalization effect is tied to the estimation of the travel cost perceived by consumers; high travel cost would imply lower substitution among stores and hence lower cannibalization. The fourth issue that complicates the inference of cannibalization is that firms might be strategic in choosing favorable locations for their new stores. Although we can control for the observed characteristics, the presence of unobserved (to the researcher) demand drivers would bias our estimates of travel cost and, hence, cannibalization. Intuitively, if new stores are opened in attractive locations, their addition is likely to have limited effect on incumbents. This would lead us to infer little cannibalization and, hence, overestimate travel cost.

In view of these issues, we develop a demand model that accounts for dynamics in goodwill, location endogeneity, and spatial competition between geographically proximate retail outlets. In addition, our demand model can account for time-varying competition from other chains via the changes in the retail configuration of these chains (via opening and closing of outlets) over time (see Online Appendix D, available at http://sitemaker.umich.edu/s.sriram/files/ food_paper_appendices.pdf). We calibrate the model on data for a U.S. fast food chain in a large U.S. city for a 36-month period. The retail chain in question has several outlets located in different parts of the metropolitan area with some store openings and closures during the period of analysis. In addition, the data contain monthly sales information at the individual store level as well as time-varying store-level attitudinal measures on customer satisfaction.

The results from our analysis reveal that the focal chain experienced a significant increase in its goodwill during the period of our analysis. Therefore, ignoring these dynamics would have led to a serious underestimation of the cannibalization effect. The results suggest that, on average, $86.7 \%$ of a store's sales constitute incremental purchases with the rest derived from cannibalization from nearby stores belonging to the chain. However, there is significant heterogeneity across stores with the cannibalization percentage ranging from a low of $5.14 \%$ to a high of $17.5 \%$. As regards the individual stores that get cannibalized, we find significant decay in cannibalization with distance such that when the distance between stores increases by one mile, the sales lost due to cannibalization decreases by $29.8 \%$; there is virtually no cannibalization at a distance of 10 miles. Furthermore, we used policy simulations to infer the overall 
growth in sales that would compensate an individual franchisee for the adverse effect of a new store opening in its vicinity. The results suggest that, on average, opening of a new store within three miles would require a $24.8 \%$ growth in overall chain sales over a two-year period. This can be accomplished by increasing the advertising outlay by approximately $125 \%$.

This paper makes the following contributions to the literature. First, we develop a demand model to infer the effect of new store openings while parsimoniously accounting for (a) competition between geographically dispersed entities, (b) location endogeneity, and (c) dynamics in goodwill. Substantively, the model helps us understand the extent to which new outlets added by the chain brought in additional sales as opposed to cannibalizing other stores operated by the chain. Considering that the lack of sales data has constrained researchers to infer the degree of substitution among fast food outlets based on spatial price variation (see Kalnins 2003, Thomadsen 2005), we believe that our research will shed some light on this issue with a much richer data set. Furthermore, we discuss how managers can use the model presented in this paper to (a) isolate locations that can be closed by identifying stores that yield the lowest marginal benefit to the chain and (b) address cannibalization concerns of franchisees.

This rest of this paper is organized as follows. We first review research related to this paper. We then present the demand model. Next, we describe the data. Subsequently, we discuss the estimation of the model given the data at hand. We then present our empirical results based on the fast food category and discuss their implications. Finally, we provide some concluding comments.

\section{Related Research}

Given that this paper investigates spatial competition in a dynamic environment, it is related to three streams of literature: (a) gravity models, (b) dynamic models, and (c) models of entry and exit. We discuss these in order.

The first stream of literature considers the territorial reach of individual stores as well as how competition between stores varies as a function of the distance between them. As discussed above, retail outlets located close to one another are more likely to compete for the same set of customers. Likewise, outlets located close to areas with high population density are likely to have a greater captive market and, hence, higher demand potential. Both these aspects of geographic competition have been studied in the past using gravity models (Reilly 1931, Huff 1964, Huff and Batsell 1977), as well as discrete choice models of consumer preference (e.g., Craig et al. 1984, Fotheringham 1991, Rust and Donthu 1995). As noted earlier, these studies have mostly used simulations or conjoint and/or survey data to examine retailer location decisions. Furthermore, these models account for the waning competition between retail outlets with distance because of travel costs incurred by customers (Bell et al. 1998). As a result, retailers planning on opening a new store need to consider how many outlets they currently have in its vicinity to infer the cannibalization effect. Kalnins (2004) considered the cannibalization effect of such territorial encroachment in the context of the Texas lodging industry in the 1990s. He found that the addition of a new unit has an adverse effect on the incumbents in its vicinity in case of franchises but not when these units are company owned. In his study of the spatial competition between movie theaters, Davis (2006) explicitly accounted for the travel costs incurred by customers. ${ }^{1}$ Thus, movie theaters located close to each other compete more fiercely than theaters that are farther away. Therefore, unlike in Kalnins (2004), his model accounts for the waning effect of spatial competition with distance. In our application, we use an approach similar to Davis's (2006). However, in view of the dynamic nature of the demand that we face in our application, we extend our analysis to investigate the source of these dynamics.

Therefore, the second stream includes studies that account for dynamics of the model parameters over time. The simplest and most flexible approach to capture dynamics would be to estimate time specific fixed effects. However, this would require estimation of a large number of parameters. Furthermore, we cannot directly infer how the various drivers influence these dynamics. To circumvent these issues, researchers have used expectations-based approaches wherein the time-varying parameters are a function of some covariates and an error. For example, Jedidi et al. (1999) accounted for the effects of advertising and promotions on dynamic brand preferences for packaged goods. Sudhir et al. (2005) modeled timevarying competition and investigated the effects of the dynamics in competitive intensity on prices. However, in the expectations-based approach, only the error variance is estimated. Hence, the expectationsbased approach is not amenable to the reconstruction of parameter paths over time (van Heerde et al. 2004). In contrast, the filtering in state-space models enables us to parsimoniously reconstruct the parameter paths over time. In addition, the approach can accommodate the role of drivers of these dynamics. In view of these benefits, there have been several applications of state-space models in the marketing literature. For example, Xie et al. (1997) and Putsis (1998) used a state-space model based on the Kalman filter

\footnotetext{
${ }^{1}$ Thomadsen (2005) used a similar model to infer travel cost. However, as discussed earlier, his analysis was based on cross-sectional data of geographic dispersion of prices.
} 
to estimate time-varying parameters in the context of new product sales. Other papers that have captured dynamics using state-space models include those by Naik et al. (1998), Akcura et al. (2004), Neelamegham and Chintagunta (2004), van Heerde et al. (2004), Naik et al. (2005), and Sriram et al. (2006). As in these papers, we use a state-space model to capture the dynamics in goodwill. Although simpler alternatives might exist, our objective is also to provide a "comprehensive" framework within which issues of goodwill can be addressed as well. Specifically, the state-space model helps us to understand the longterm role of drivers, such as advertising, in building goodwill.

As discussed earlier, while inferring travel cost and cannibalization, we need to consider the possibility that location choices are made strategically. In this regard, we can draw from the literature on entry and exit (see Bresnahan and Reiss 1991, Berry 1992). This literature treats the number of firms in the market as an equilibrium outcome of a game played by multiple potential entrants. Intuitively, the equilibrium assumption exploits the fact that the number of firms in a market is likely to be indicative of its attractiveness and can thus be used to control for unobserved characteristics. Invoking the equilibrium assumption, however, requires the researcher to make strong assumptions about the nature of the agents' objective functions as well as the distribution of the error terms (Manuszak and Moul 2008). Moreover, it typically requires either an a priori definition of geographically isolated markets (see Singh and Zhu 2008) or discretization of possible entry locations and distances (Seim 2006, Datta et al. 2008). However, given the contiguous nature of our metropolitan market as well as the fairly even distribution of outlets, such as assumption does not appear to be appropriate in our context. We exploit the panel nature of our data and control for the unobserved cross-sectional demand drivers by including store fixed effects. In addition, we discuss an alternative approach to correcting for location endogeneity without invoking the equilibrium assumption when one only has cross-sectional data.

\section{Model}

Consider a market that is divided into $M$ mutually exclusive and collectively exhaustive regions. In our application, we use census tracts to describe such regions. Let the indirect utility that consumer $i$ living in census tract $m, m=1,2, \ldots, M$, derives from store $s, s=1,2, \ldots, S$, belonging to the focal chain, at time $t$ be defined as

$$
U_{i m s t}=\bar{\alpha}_{s}+\alpha_{t}+\theta H_{t}+\beta X_{s t}+\psi d_{m s}+\xi_{s t}+\varepsilon_{i m s t},
$$

where $\alpha_{t}$ is the goodwill for focal chain at time $t, H_{t}$ corresponds to factors such as holidays that affect the utility from all stores, and $X_{s t}$ captures store-level time-varying characteristics such as price and measures of performance such as satisfaction scores. The term $\bar{\alpha}_{s}$ captures the fixed effect for store $s$. We include store fixed effects in the model to capture the timeinvariant observed and unobserved characteristics such as format (such as free-standing units (FSUs) versus mall location), proximity to highways, etc., that affect the attractiveness of the corresponding stores. The parameters $\theta$ and $\beta$ capture the effect of holidays and store-specific characteristics on utility. The term $\xi_{s t}$ captures store, chain, and time-varying demand shocks that are observed by the consumer and the chains but not by the researcher, and $\varepsilon_{i m s t}$ captures the consumer-specific idiosyncratic error. The term $\psi d_{m s}$ captures the effect of the distance between the centroid of census tract $m$ and store $s, d_{m s}$, on the utility that consumers from the tract derive from the store.

If the consumer decides not to visit any of the stores belonging to the chain at time $t$, she would derive a utility $U_{i m 0 t}$ such that

$$
U_{i m 0 t}=\varepsilon_{i m 0 t} .
$$

If we assume that the consumer-specific idiosyncratic error terms for the focal chain and the outside option, $\varepsilon_{i m s t}$ and $\varepsilon_{i m 0 t}$, follow an independent and identically distributed type I extreme value distribution, the probability that consumer $i$ belonging to census tract $m$ would choose store $s$ at time $t$ can be written as

$$
\begin{aligned}
& P_{\text {imst }} \\
& \quad=\frac{\exp \left(\bar{\alpha}_{s}+\alpha_{t}+\theta H_{t}+\beta X_{s t}+\psi d_{m s}+\xi_{s t}\right)}{1+\sum_{s^{\prime} \in S_{t}} \exp \left(\bar{\alpha}_{s^{\prime}}+\alpha_{t}+\theta H_{t}+\beta X_{s^{\prime} t}+\psi d_{m s^{\prime}}+\xi_{s^{\prime} t}\right)} \\
& =\frac{\exp \left(\delta_{s t}+\psi d_{m s}\right)}{1+\sum_{s^{\prime} \in S_{t}} \exp \left(\delta_{s^{\prime} t}+\psi d_{m s^{\prime}}\right)},
\end{aligned}
$$

where $S_{t}$ is the sets of stores operated by the focal chain at time $t$, and

$$
\delta_{s t}=\bar{\alpha}_{s}+\alpha_{t}+\theta H_{t}+\beta X_{s t}+\xi_{s t}{ }^{2}
$$

We can now write the market share of store $s$ at time $t$ as

$$
S_{s t}=\sum_{m=1}^{M} P_{i m s t} \times W_{m}
$$

where the weight $W_{m}$, such that $\sum_{m=1}^{M} W_{m}=1$, is the proportion of the total metropolitan market population represented by tract $m$.

\footnotetext{
${ }^{2}$ In addition, one can incorporate consumer heterogeneity in the goodwill for the chain. However, as we discuss below, the model specification we currently have circumvents the independence of irrelevant alternatives (IIA) problem. We found that adding unobserved heterogeneity increases the computational burden with limited marginal benefit.
} 
Overall, a negative $\psi$ (i.e., a positive travel cost) would imply that consumers would prefer to dine at outlets nearby than those located farther away. Thus, all else being equal, two outlets located closer to each other would compete more fiercely for the same set of customers than those located father away from each other, and therefore experience greater cannibalization. Furthermore, the specification of the model at the census tract level implies that there would be greater (lower) substitution between stores located closer to (farther away from) each other. Thus, the model circumvents the IIA substitution pattern implied by the standard logit model. In a similar vein, Equation (4) implies that stores that are located in high population areas are likely to have higher demand.

\subsection{Discussion}

A few additional points about the model are worth noting. First, the no purchase option captures the extent to which consumers choose other non-fast food options that are not included in the model as well as eating at home. Because the utility of the outside option is fixed, any evolution in consumers' fast food consumption behavior over time would be captured by $\alpha_{t}$ in Equation (1a). As we discuss subsequently, we partly account for this evolution in our empirical application by incorporating information on per-capita fast food consumption over time while defining the market size. Therefore, we need to exercise some caution in referring to $\alpha_{t}$ as goodwill. ${ }^{3}$ Second, although the model presented here does not formally account for competition from other chains, it can be readily extended to accommodate that. However, calibrating such a model would require store-level sales and price data for multiple chains. However, given that the fast food industry is notoriously secretive in sharing store-level sales data (Kalnins 2003), researchers (and managers) are more likely to encounter scenarios where they have access to sales data from only one chain. Under such a scenario, we can use publicly available data on the number of stores belonging to various competitors over time to account for competitive effects. In our context, these data revealed limited temporal variation in the number of stores belonging to competing chains, although there was significant cross-sectional variation. Given that our model includes store fixed effects, adding competition is likely to have limited additional explanatory power. ${ }^{4}$ However, if the model

\footnotetext{
${ }^{3}$ If these factors are salient, they would be captured by the error term in the system equation, $\boldsymbol{s}_{t}$, in Equation (5).

${ }^{4}$ We can formulate a model wherein competition from stores belonging to other chains enter in a limited way by treating each store as another inside option whose utility is specified as
}

did not include store fixed effects, we would have to formally account for the cross-sectional differences in competitive environment across stores.

\subsection{Modeling Dynamics in Goodwill}

Note that in Equation (3b), we allow the parameter $\alpha_{t}$, which captures the goodwill for the focal chain, to vary over time. Consistent with the notion that advertising has an effect on the chain's goodwill over time (see, for example, Jedidi et al. 1999), we model the dynamics of the mean (across consumers) goodwill as

$$
\begin{aligned}
\alpha_{t}=\lambda \alpha_{t-1}+\varpi h\left(\operatorname{Ad}_{t}\right)+s_{t}, \\
\text { where } \varsigma_{t} \sim \mathrm{N}\left(0, \sigma_{s}^{2}\right),
\end{aligned}
$$

where $\alpha_{t}$ is the goodwill for the focal chain, and $\operatorname{Ad}_{t}$ is the level of advertising expenditure by the focal chain, both at time $t .^{5}$ As in Dube et al. (2005), we use $h\left(\operatorname{Ad}_{t}\right)=\ln \left(1+\operatorname{Ad}_{t}\right)$ to capture the diminishing effect of advertising as well as to accommodate instances where the firm did not spend anything on advertising. The parameter $\varpi$ captures the contemporaneous effects of advertising on the chain's goodwill. The parameter $\lambda$ captures the extent to which goodwill carries over from period to period and can be interpreted as a measure of inertia in goodwill. The error term $s_{t}$ captures the change in goodwill at time $t$ that is not explained by either the carryover of goodwill from the previous period or the level of advertising.

\section{Data}

We use monthly sales data from a chain of fast food restaurants in a large U.S. metropolitan area spanning 36 months from October 2002 through September 2005. The chain operated 66 restaurants in the city, offering food such as hamburgers, tacos, and chicken. Almost all of these stores were operated by franchisees. Each store was in one of the three different formats-a free-standing unit (FSU), inside a mall (Mall), or drive-through only (DTO). Of these, FSUs (approximately 70\%) were the most common followed by outlets inside malls (approximately $24 \%$ ).

a function of distance from each census tract $m$ with the same distance parameter $\Psi$. Our estimation of the model with competition included in this fashion yielded results similar to the model without competition. We report these estimates in Online Appendix D.

${ }^{5}$ The model implies that all stores belonging to the chain experience the same change in goodwill. To check whether the chain experienced different growth rates in different areas of the city, we estimated a model that captured the evolution in goodwill via quarterly time fixed effects (recall that the data are monthly) as well as interactions of these time fixed effects with store fixed effects to accommodate differential growth rates in different local markets. Based on the results, we could not reject the null hypothesis that the change in goodwill was the same across markets. We thank an anonymous reviewer for suggesting this analysis. 
The remaining $6 \%$ were DTOs. The data contain information on the monthly sales (in units and dollars) of each item on their menu, the price of each item, street address of each location, and monthly advertising expenses for the chain in the whole metropolitan market. In addition, the firm conducted quarterly surveys in each of its locations to assess satisfaction of its customers with various aspects of service.

We supplemented these data with information pertaining to the population characteristics in various parts of the city from the Census Bureau (http://www .census.gov). ${ }^{6}$ To capture the geographic variation within the city, we collected these data at the census tract level. The city is divided into 568 mutually exclusive census tracts. These census tracts differ significantly in terms of their population and land area. Furthermore, because there are significantly more tracts than stores and the median tract area is only approximately 2.5 square miles, each store is likely to serve multiple census tracts.

\subsection{Operationalization of Variables}

4.1.1. Chain-Level Variables. There are two main variables that affect demand at the chain level: advertising and seasonality. Regarding advertising, the data contain information on the monthly ad expenses incurred by the chain in the city. Regarding seasonality, the data revealed a significant spike in sales during the holiday season. To capture this, we used a holiday dummy ( 1 for December and 0 otherwise) as a demand shifter for the entire chain.

4.1.2. Store-Level Variables. The dependent variable in our analysis is the market share of each individual store. To compute this market share, we need to know (a) the sales volume in each store in each period and (b) the size of the overall market. We discuss how we compute sales volume here, and later we discuss the operationalization of overall market size. A key problem in computing unit sales volume is that the chain offers numerous items in its menu including drinks and side orders such as fries. A sizeable fraction of these transactions correspond to side items such as drinks and fries. Clearly, it would be inappropriate to count these along with lunch items such as sandwiches as separate sales units. Hence, we identified items on the menu that would constitute a meal (breakfast, lunch, or dinner). We then computed the number of such meal items that were sold in each store in each time period to compute the unit sales volume. However, the total number of transactions and the transactions corresponding to meal items exhibit a correlation of 0.897 . Therefore, we do

${ }^{6}$ We obtained these data from a Census Bureau database called Landview for the year 2003. not expect the results to change significantly if we were to use the total number of transactions instead.

Another variable of interest at the store level is the price. Once again, given the disparate nature of menu items, we need to identify a metric of price that acts as a price index. ${ }^{7}$ In our empirical application, we used the price of the largest selling combination meal as the price index. This was the largest selling item across all stores and constituted $25 \%$ of sales in units (and $37 \%$ by revenue) of all items that we classified as meals. ${ }^{8}$ We present the temporal variation as well as the cross-section range of the price of the largest selling combination meal in Figure 1. The figure suggests that there is some temporal and cross-sectional variation in prices. On average, the difference between the maximum price and the minimum price for the largest selling combination meal was about 16 cents.

An additional driver of store performance in our analysis is customer satisfaction. The firm conducted quarterly surveys in each of its stores to assess customer satisfaction on a scale of $1-5$, with 1 being the lowest. Because the various measures of satisfaction were highly correlated, we used the average (across all respondents) overall satisfaction measure in our model estimation. Because the sales data were at the monthly level, we used the same satisfaction measure for all three months in the quarter.

4.1.3. Census Tract-Level Measures. For each census tract, we need a measure of its attractiveness in terms of size relative to the overall market. A direct measure of the size of each tract is its population. We obtained these data from the census bureau. In our application, we defined the total market size based on the number of fast food consumption occasions for the entire population in the metropolitan area. We obtained the total population of the city by adding the population of all the census tracts in the city. To account for the change in fast food consumption over time, we obtained annual consumer expenditure survey data on "food away from home" expenditures from the metropolitan market in question. We used the time-varying price index for food away from home from the bureau of labor statistics to adjust for price changes over time. ${ }^{9}$ We then combined this with the information that an average household visited fast food restaurants eight times in a month (based

\footnotetext{
${ }^{7}$ Measures such as weighted average price across menu items are likely to induce spurious variation in prices due to aggregation.

${ }^{8}$ Thomadsen (2005) similarly uses the prices of the "signature sandwichs" of McDonalds (the "Big Mac") and Burger King (the "Whopper") in his analysis.

${ }^{9}$ Changes in consumer expenditures could reflect changes in prices and/or changes in the frequency of eating out. Our objective is to tease out the latter by adjusting for changes in prices over time. This is what we seek to accomplish here.
} 


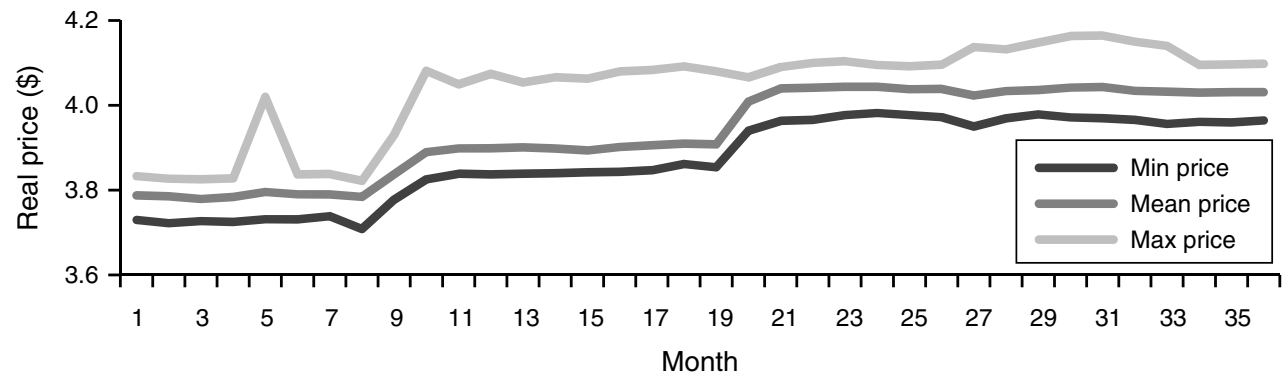

on Mintel reports) in 2006 to back out the per-capita number of visits over time. ${ }^{10}$ As in Nevo (2001), we obtained the total market size for each month by multiplying the population by this number. Based on this assumption, the average unconditional market share for the chain across all periods was $0.19 \%{ }^{11}$

As discussed in the model section, the competitive environment in each census tract is a function of the distance between the tract and the individual stores. We operationalized this as the Euclidean distance between the centroid of the tract and each of the stores (see Davis 2006 for a similar operationalization).$^{12}$

\subsection{Descriptive Statistics}

We present information on the average number of stores, average unit sales per store, as well as the average price index in Table 1. To highlight differences across formats, we present these descriptive statistics by store format. Whereas the number of DTOs remained constant throughout the period of our analysis, the number of stores in the other two formats changed over time because the firm opened six new stores during the period of our analysis. Five of these stores were FSUs and one was opened inside a mall. Moreover, eight of these stores experienced temporary closing for a few months during the period of our analysis. Turning now to the average sales per store, the values in Table 1 imply that FSUs generated the highest sales per store followed by DTOs. Average sales in stores located inside malls were approximately half of the sales generated in FSUs. This is probably because of greater competition inside malls.

\footnotetext{
${ }^{10}$ We also estimated the model under the assumptions of 4 and 12 visits per month and obtained very similar results. These results can be obtained from the authors upon request.

${ }^{11}$ Note that the unconditional market shares when one also includes the outside good tend to be relatively small (see Nevo 2001 for a discussion of this and its implications).

${ }^{12}$ Although Euclidean distance is likely to be a noisy measure of the distance one has to travel to get to a given store, Davis (2006) cites past research using data from the New York State Department of Transportation to argue that the straight line distance could be a good proxy for travel time.
}

The average prices in FSUs were the highest, though the differences across the formats were quite small.

To understand the temporal variation in performance, we computed the average values of some key metrics such as total sales, number of stores, and average sales per store for the first and last 12 months of the data. We expect that the use of average values across a 12-month window would smooth out the effect of seasonal fluctuations. We present the unit sales, number of stores, and advertising expenditures for the two 12-month windows as well as the corresponding changes in Table 2 . These results highlight several interesting features of the data. First, the sales volume for the chain increased by $16.93 \%$ during the period of our analysis. Therefore, the chain seems to have experienced a significant growth in its performance. As discussed above, the chain also opened several new stores during this period. From Table 2, we can see that the number of stores increased by approximately $9.44 \%$ between the beginning and the end of the data. Therefore, part of the increase in total sales for the chain may be attributed to the opening of new stores. Moreover, we can see from Table 2 that the average sales per store increased by $6.84 \%$ during this period. Hence, some part of the gain in total sales can also be attributed to the greater performance of individual stores. However, note that this increase in average sales per store is lower than the increase in total sales at the chain level.

There are several plausible reasons behind this increase. First, Table 2 indicates that the firm significantly increased its advertising expenditure in this market (by approximately 80\%) between the first and the last years of our analysis. This is likely to have increased goodwill. Second, recall that of the six new stores that were introduced, five were FSUs. Because FSUs had the best performance among the three formats in terms of average sales per store, the new store introductions increased the proportion of FSUs in the pool. This could have contributed to the increase in the average sales per store. Finally, the higher performance could have been driven by an increase in customer satisfaction in these stores. Although average satisfaction across stores did not show much change, 
Table 1 Descriptive Statistics by Store Format

\begin{tabular}{lccccc}
\hline Store format & $\begin{array}{c}\text { Minimum } \\
\text { number of stores }\end{array}$ & $\begin{array}{c}\text { Maximum } \\
\text { number of stores }\end{array}$ & $\begin{array}{c}\text { Average number } \\
\text { of stores }\end{array}$ & $\begin{array}{c}\text { Average sales per } \\
\text { store ('000 units) }\end{array}$ & $\begin{array}{c}\text { Average price } \\
\text { (\$) }\end{array}$ \\
\hline Drive-through stores & 4 & 4 & 4 & 40.93 & 3.93 \\
Free-standing units & 39 & 46 & 42.67 & 53.36 & 3.95 \\
Mall stores & 13 & 15 & 14.64 & 27.49 & 3.90 \\
\hline
\end{tabular}

Table 2 Change in Unit Sales, Number of Stores, and Advertising

\begin{tabular}{lccr}
\hline & $\begin{array}{c}\text { Average for } \\
\text { first 12 months }\end{array}$ & $\begin{array}{c}\text { Average for } \\
\text { last 12 months }\end{array}$ & \% increase \\
\hline Total sales (thousand units) & $2,610.28$ & $3,052.25$ & 16.93 \\
$\begin{array}{l}\text { Average number of stores } \\
\text { Average sales per store } \\
\quad \text { (thousand units) }\end{array}$ & 58.25 & 63.75 & 9.44 \\
$\begin{array}{c}\text { Advertising expenses } \\
\text { (thousand \$) }\end{array}$ & 44.8 & 47.88 & 6.84 \\
\hline
\end{tabular}

the satisfaction scores at individual stores did exhibit significant changes over time.

Notwithstanding these, the increase in the number of stores would have increased the extent of competition faced by some extant stores. Although these new stores might have added some new customers, we would also expect some cannibalization from older stores. We would expect that stores that saw new stores open in their neighborhood would have experienced a lower growth than stores that did not. To illustrate this point, we separately computed the growth in the average sales per store between the first and last years for the two groups. This analysis revealed that the stores that did not see new entrants in their neighborhood (as defined by a 10 mile radius), but in otherwise comparable environments, experienced a higher than average growth of approximately $13.6 \%$. On the other hand, stores that saw new entrants in their neighborhood grew by only $3.3 \%$. This difference in growth between the two groups might be indicative of the effect of cannibalization. To see if this effect varied with proximity to the new store, we plotted the growth rate of the affected stores against their distance from the new store in Figure 2. The figure reveals that stores that were farther away from the new store experienced higher growth rates on average than stores that were closer by. Therefore, there seems to be some indication of the diminishing effect of new stores with distance from existing stores.

An additional complication in the identification of travel cost and, hence, with inferring cannibalization is that the chain might have strategically opened outlets in areas that had favorable demand conditions and/or competitive environment. Under such a scenario, tracts with higher (more attractive) unobserved demand characteristics are likely to have more stores located in their vicinity compared to those with less attractive demand characteristics. Consequently, we would observe that the opening of a store in an area with a high density of stores does not adversely affect the demand of incumbent stores although they are located in close proximity. Therefore, a model that ignores location endogeneity is likely to overestimate travel cost, i.e., each outlet will appear to have greater competitive clout than is actually the case. To assess if location endogeneity is a serious concern in our application, we compared the observable characteristics of census tracts with varying numbers of stores located within two miles of their centroids. We present this comparison in Table 3. The results reveal that tracts that have higher population density, and lower area, as well as those located close to highways, tend to have higher concentration of stores. Although one can account for these observed characteristics in the demand model, one cannot rule out the presence of unobserved characteristics that can drive location choice. Therefore, the estimation strategy needs to employ an approach that would account for location endogeneity.

The above discussion highlights the complexity of understanding (a) the role of new store introductions

\section{Figure 2 Relationship Between Percentage of Change in Sales and Distance from New Store}

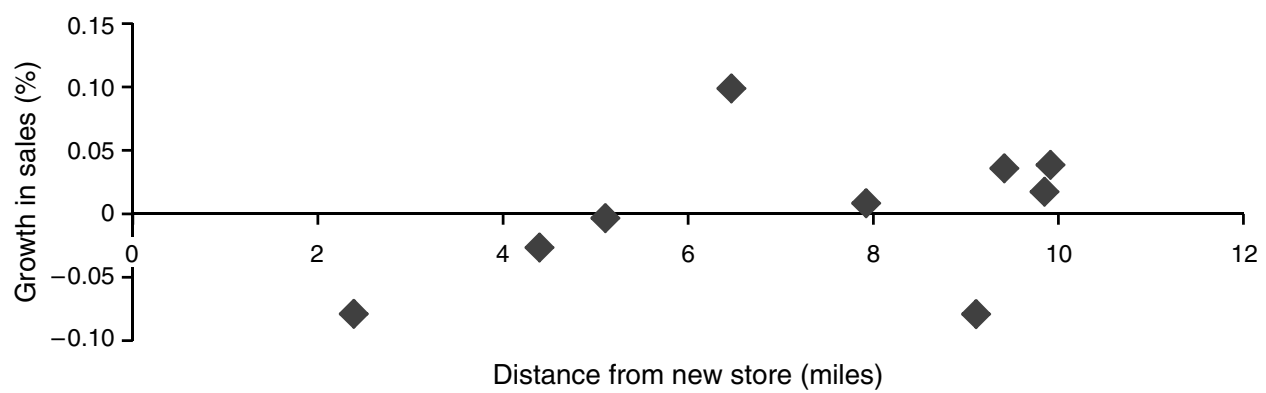


Table 3 Characteristics of Census Tracts with Different Number of Outlets Within Two Miles

\begin{tabular}{lcccc}
\hline & \multicolumn{4}{c}{ Number of outlets within two miles } \\
\cline { 2 - 5 } Characteristic & 0 & 1 & 2 & $\geq 3$ \\
\hline Area (sq. miles) & 9.69 & 2.54 & 2.1 & 1.59 \\
Population density & 2,016 & 3,176 & 4,835 & 4,794 \\
$\%$ close to highway & NA & 52 & 80 & 93 \\
\hline
\end{tabular}

in driving the performance of stores in its neighborhood and (b) the overall performance of the chain over time. Thus, we cannot infer the cannibalization effect by merely comparing the sales of incumbent stores before and after a new store opened. Rather, as motivated elsewhere in this paper, we need a comprehensive model that accommodates dynamics in goodwill while inferring cannibalization effects.

\section{Estimation}

\subsection{Identification}

There are two broad concerns regarding identification of the model parameters: (a) presence of sufficient variation in the data and (b) endogeneity issues that might lead to biased estimates even in the presence of sufficient variation in the data. Below, we discuss these with respect to the key parameters of interest.

5.1.1. Distance Effect. As discussed above, a key complicating factor in inferring the distance effect (i.e., travel cost) is that the firm might have strategically chosen locations with favorable demand conditions and/or competitive environment. In our application, we exploit the panel nature of our data and account for location endogeneity by including store fixed effects. These store fixed effects control for all observed and unobserved store characteristics, which would have entered the error term in their absence (Evans et al. 1993). ${ }^{13}$ Consequently, in our application, the travel cost parameter is identified based on two sources of temporal variation. First, the model exploits the temporal variation in prices and satisfaction scores at individual stores for identification. Therefore, the extent to which a price (or satisfaction score) change at one store differentially affects demand at stores located at different distances from it helps in pinning down the travel cost. In our data, each store has 4.3 stores belonging to the focal chain within five miles, on average. Thus, we conjecture that variation in sales induced by changes in price

\footnotetext{
${ }^{13}$ Whereas the panel nature of our data enables us to control for endogeneity due to unobserved cross-sectional characteristics, this would not be viable with cross-sectional data. In Online Appendix B, we discuss an alternative approach to control for location endogeneity without invoking the equilibrium assumption.
}

and satisfaction scores from neighboring stores is sufficient to pin down the travel cost. The second source of variation comes from the entry and exit of outlets belonging to the focal chain. As in the case of price variation, the extent to which the entry or exit of an outlet affects the demand at the focal chain's stores located at various distances helps in identifying the distance effect. In our data, 24 of the 66 stores saw an entry from another store belonging to the focal chain store within five miles. Moreover, the average number of stores within five miles of each store increased by approximately $12 \%$ during the period of our analysis. Together, we expect that this change in competitive environment around stores will provide sufficient variation to identify the distance effect.

One potential caveat is that although store fixed effects account for location endogeneity due to unobserved cross-sectional demand characteristics, they would not control for endogeneity of store opening and closure decisions made in response to timevarying characteristics (Manuszak and Moul 2008). For example, if census tracts experienced differential growth in goodwill, the firm might have opened new outlets closer to the tracts with favorable growth prospects. To verify whether such differential growth rate is likely to be a problem, we estimated a model with store fixed effects, quarter fixed effects, the interaction of the store and quarter fixed effects, and the effect of the holiday season. Whereas the quarter fixed effects captured the overall evolution in chain goodwill, their interaction with store fixed effects (rather the $n-1$ store dummies) captured whether goodwill for some stores evolved at a differential rate. The results showed that none of the interactions were statistically significant. Consequently, we believe that differential growth patterns in goodwill are unlikely to be an issue in our context. Nevertheless, it is still possible that the timing of entry was based on other time-varying characteristics, and we acknowledge this as a potential caveat.

5.1.2. Price Effect. The price effect is identified based on the extent to which sales vary with price after accounting for other demand drivers. As discussed in an earlier section, the data reveal the presence of both cross-sectional and temporal variation in prices. Nevertheless, as in the case of location choices, the firm might have set prices for the items on its menu after considering the local market conditions. To account for price endogeneity, we need instrumental variables that would be uncorrelated with demand characteristics but are correlated with prices. In our application, we use factor costs as instruments. The argument behind the validity of these instruments is that although these costs are likely to influence the prices, they are unlikely to be driven by changes in demand conditions, at least in the short run. In the 
Figure 3 Advertising and New Store Openings

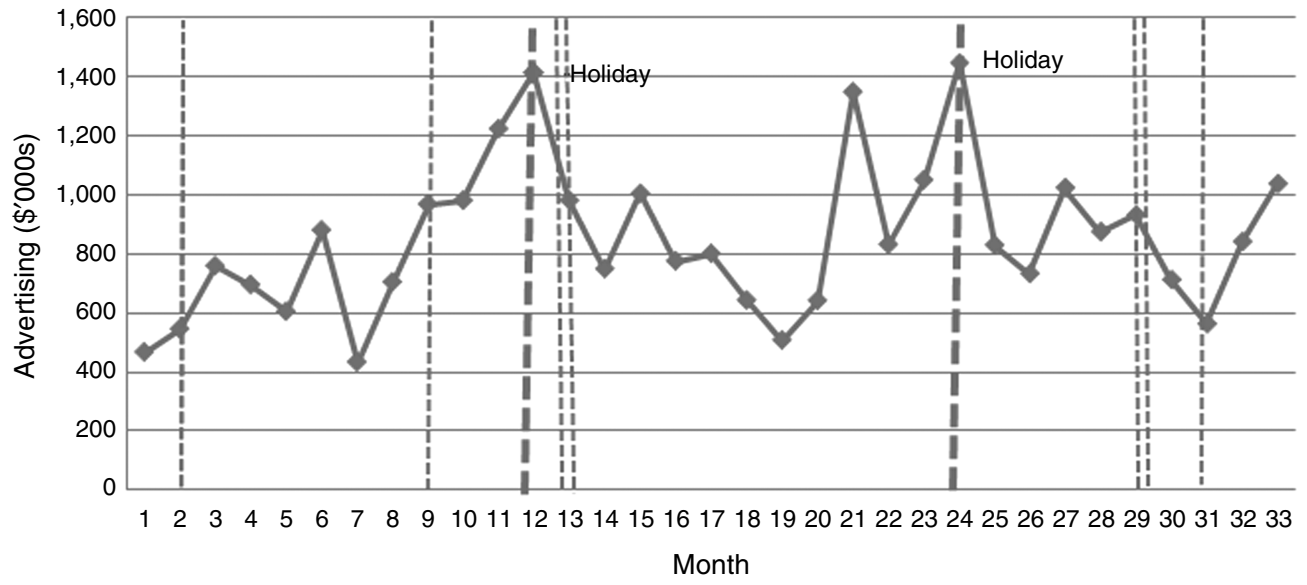

Note. Thin vertical lines show new store openings and thick vertical lines show holiday periods.

empirical application, we use three factor costs: cost of bread, cost of meat, and wages of employees in the accommodation and food industry. We obtained these data from the Bureau of Labor Statistics. ${ }^{14}$

5.1.3. Advertising Effect. Recall that in our model, advertising has a contemporaneous and long-term effect on goodwill and, consequently, on demand. The contemporaneous advertising effect is identified based on the comovement between advertising expenditures and the average sales per store after accounting for other factors that might affect demand. On the other hand, the long-term effect (via the carryover parameter) is identified based on the extent to which a shock to advertising budget in a given period induces changes in demand in the future after accounting for the other potential drivers. Our data reveal significant variation in advertising levels over time (standard deviation, \$314,790; coefficient of variation, 0.439). Overall, these suggest that there is sufficient variation in the data to pin down the advertising effects.

A potential concern is that advertising expenditures could have been endogenously determined by the focal firm in several different ways. First, advertising could have been used as a mechanism to inform consumers about price promotions. Because we believe that the price variable is likely to be correlated with the demand shocks, one could argue that the same could be true for advertising. Second, the opening of new outlets could be accompanied by increased advertising expenditures. For example, researchers have argued that franchisors tend to increase advertising expenditures to overcome franchisee resistance

\footnotetext{
${ }^{14}$ Although the factor costs only have temporal variation, the inclusion of store fixed effects as exogenous variables would imply that the predicted prices have both cross-sectional and temporal variation. An ordinary least squares regression of the instruments on price yielded an $R^{2}$ value of 0.54 .
}

to the opening of new outlets in their vicinity (see, for example, Kaufmann and Rangan 1990). If this is true, we should observe a positive relationship between advertising and the number of outlets. Third, advertising expenditures could be set in anticipation of seasonal demand changes. In our context, the sales data reveal significant peaks during the holiday season. In addition, the opening of a new store is also likely to be accompanied by a temporary spurt in advertising expenditures. To investigate if this is indeed the case, we plotted advertising expenditures over time (see Figure 3) along with markets for new store openings (thin vertical dotted lines) and the holiday season (thick vertical dotted lines). Clearly, whereas we see spikes in advertising expenditures during the holiday season, there is no systematic variation in advertising with new store openings. To formalize this analysis, we regressed advertising on average (across stores) prices, number of outlets during each period, and dummies for new store openings and the holiday season. Of the four variables, only the holiday dummy had a significant relationship with advertising. Because we explicitly account for holidays as a potential demand shifter, we can rule out this source of endogeneity. Therefore, we believe that advertising endogeneity is likely to be a limited issue in our application. Nevertheless, if the focal firm sets its advertising budget in response to changes in competitors' budgets (which would be a part of the demand shock), this would induce correlation between the demand shock and advertising. Because we cannot rule this out with existing data, this is a worthwhile avenue for future research.

\subsection{Estimation Details}

The objective of our estimation is to recover three sets of parameters in Equations (3b) and (5): (a) parameters $\Theta_{1}=\{\theta, \lambda, \varpi\}$ in Equations (3b) and (5), which 
correspond to the mean goodwill and other response parameters that influence the utility of all the stores belonging to the focal chain (i.e., chain-level parameters), (b) parameters $\Theta_{2}=\{\beta\}$ in Equation (1) that capture the effects of consumers' valuations of the characteristics of individual stores (including price and store format), and (c) $\Theta_{3}=\psi$, the effect of distance. ${ }^{15}$ We estimate all the parameters simultaneously, although we discuss the estimation of different sets of parameters sequentially.

As in Berry et al. (1995), for a given set of the census tract-level parameters $\left(\Theta_{3}\right)$, we can uniquely obtain the mean utilities, $\delta_{s t}=\bar{\alpha}_{s}+\alpha_{t}+\theta H_{t}+\beta X_{s t}+\xi_{s t}$, by inverting the store-level share in Equation (4). Note that although there is no proof regarding the applicability of the BLP approach to geographic markets, our application is similar to that of Davis (2006), who applied the methodology to geographic markets. ${ }^{16}$ We then proceed with the estimation as follows: (i) estimate the parameters $\Theta_{2}$ that affect the choice of a particular store belonging to the chain conditional on that chain being chosen, and (ii) estimate the chainlevel parameters, $\Theta_{1}$. To accomplish this, we need to decompose $\delta_{s t}$ into two components: the component of utility that is common to all the stores belonging to the chain and the deviations in the utilities of the individual stores belonging to the chain from this common chain-level utility. Although we can easily separate the deterministic components of these utilities, there are no such corresponding components for the unobserved (by econometrician) component of the utilities, $\xi_{s t}$. Therefore, we set one of the chain's stores that was open throughout the time series as the base store (hereafter indexed as store 1) and set its unobserved component of utility (i.e., $\xi_{1 t}$ ) as the overall chain-level unobserved component $\left(\xi_{f t}\right)$, i.e., $\xi_{t}=\xi_{1 t} \cdot{ }^{17}$ We now discuss the estimation of store-level and chain-level parameters.

5.2.1. Estimating the Parameters That Affect Store Choice $\left(\Theta_{2}\right)$. Subtracting the mean utility of the base store from those of the remaining stores at time $t$ (from Equation $(3 b))$, we have

$$
\delta_{s t}-\delta_{1 t}=\delta_{s t}^{\prime}=\Delta \bar{\alpha}_{s}+\beta \Delta X_{s t}+\Delta \xi_{s t}, \quad s=2, \ldots, S,
$$

where $\Delta \alpha_{s}=\alpha_{s}-\alpha_{1}, \Delta X_{s t}=X_{s t}-X_{1 t}$, and $\Delta \xi_{s t}=\xi_{s t}$ $\xi_{1 t}$. In Equation (6), $\delta_{s t}^{\prime}$ is known because we have

\footnotetext{
${ }^{15}$ The estimation algorithm used here is similar to the one proposed by Sriram et al. (2006).

${ }^{16}$ We would like to thank an anonymous reviewer for pointing out that geographic markets need not have quasi-concave distributions. Hence, there is no proof that the BLP methodology is appropriate.

${ }^{17}$ Intuitively, if we were to estimate a model with store fixed effects, we may have to set one of them to zero because we are estimating an overall chain-level goodwill. The fixing of one of the $\Delta \xi_{s t}$ terms to zero is similar to that. We also found that the results were robust to our choice of the base store.
}

already recovered $\delta_{s t}$ by inverting the store-level share in Equation (4). Likewise, we can calculate $\Delta X_{s t}$ for each of the nonfocal stores based on their characteristics and those of the focal store.

5.2.2. Estimating the Chain-Level Parameters $\left(\Theta_{1}\right)$. Recall that conditional on $\Theta_{3}$, we have thus far obtained the mean utilities $\delta_{s t}$. Conditional on $\Theta_{2}$, we need to estimate the parameters that influence choices at the chain level, $\Theta_{1}$. As we demonstrate in Online Appendix A, we can show that

$$
\begin{aligned}
\sum_{m=1}^{M} W_{m} & \left\{\ln \sum_{s \in S_{t}} \exp \left(\delta_{s t}+\psi d_{m s}\right)\right. \\
& \left.\quad-\ln \sum_{s \in S_{t}} \exp \left(\beta X_{1 t}+\psi d_{m s}+\delta_{s t}^{\prime}\right)\right\} \\
= & \bar{\alpha}_{1}+\alpha_{t}+\theta H_{t}+\xi_{t} .
\end{aligned}
$$

Note that all the terms in Equation (7) are defined at the chain level. Furthermore, the left-hand side of the equation $\left(\sum_{m=1}^{M} W_{m}\left\{\ln \sum_{s \in S_{t}} \exp \left(\delta_{s t}+\psi d_{m s}\right)-\right.\right.$ $\left.\left.\ln \sum_{s \in S_{t}} \exp \left(\beta X_{1 t}+\psi d_{m s}+\delta_{s t}^{\prime}\right)\right\}\right) \quad$ can be computed given $\Theta_{3}$ and $\beta\left(=\Theta_{2}\right)$. Because we do not observe the goodwill, $\alpha_{f t}$, in Equation (7), we use the Kalman filter algorithm, which is a recursive algorithm that is used to obtain efficient estimates of an unobserved state variable (goodwill in our case) at each period based on the information observed at that period. The Kalman filter is thus a two-equation system consisting of (i) an observation equation that relates the time-varying parameters to an observed dependent variable and (ii) a system equation that characterizes the dynamics of the time-varying parameter. In our Kalman filter system, Equation (7) corresponds to the observation equation, and Equation (5) corresponds to the system equation. Consistent with the assumptions of the Kalman filter algorithm, we need to further assume that $\xi_{t} \sim \mathrm{N}\left(0, \sigma_{\xi}^{2}\right) .{ }^{18}$ Note that this follows directly from an assumption that the unobserved error term for each store $s, \xi_{s t}$, comes from a mean zero normal distribution (see Draganska and Jain 2004 for a similar assumption of normality) because $\xi_{t}$ is the same as the unobserved error term for the base store. ${ }^{19}$

5.2.3. Overview of the Estimation Algorithm. Thus far, we have discussed estimation of $\Theta_{1}$ and $\Theta_{2}$ given the census tract-level parameters $\left(\Theta_{3}\right)$. That estimation yields the system of error terms $\xi_{t}$. Now the remainder of the estimation involves obtaining $\Theta_{3}$

\footnotetext{
${ }^{18}$ This specific parametric assumption is required to infer the unobserved state variable, i.e., the goodwill based on the Kalman filter.

${ }^{19}$ We used the Anderson-Darling test to check whether the realized values of $\xi_{t}$ are indeed normal. We could not reject the null hypothesis of normality even at a $90 \%$ confidence level.
} 
by minimizing a quadratic form of these error terms, $\xi^{\prime} Z W^{-1} Z^{\prime} \xi$, where $Z$ is the matrix of instruments and $W$ is the weighting matrix defined by $E\left[Z^{\prime} \xi \xi^{\prime} Z\right]{ }^{20}$ One way of doing this is by using a generalized method of moments procedure to estimate the parameters. Specifically, $\left\{\Theta_{1}, \Theta_{2}\right\}$ are computed in an "inner" loop, whereas the algorithm searches for $\left\{\Theta_{3}\right\}$ in an "outer" loop similar to the procedure suggested by Berry et al. (1995). For further details regarding the estimation algorithm, see Online Appendix C.

\section{Results}

We present the results from our estimation in Tables 4 and 5. The results imply that the satisfaction scores have a positive effect on the utility from dining at a particular store, whereas price has a negative effect. The corresponding average price elasticity across stores is -2.088 . The chain-level parameter estimates indicate that there is a positive and significant carryover of goodwill from period to period. This result is consistent with the findings in the literature that goodwill exhibits substantial persistence from period to period (see, for example, Jedidi et al. 1999, Sriram and Kalwani 2007). Furthermore, these results indicate that advertising has a positive and significant effect on goodwill and, hence, on store- and chainlevel sales. Similarly, the holiday season has a positive and significant effect on demand. The statistically significant effect of advertising coupled with the substantial carryover in goodwill implies that advertising has a contemporaneous as well as a long-term effect on goodwill (and on demand). The short-term (or contemporaneous) advertising elasticity implied by these estimates is 0.01 . The corresponding total elasticity (including the long-term effect of advertising) is 0.07 . These elasticity estimates are in line with those reported elsewhere in the literature (see, for example, Assmus et al. 1984, Lodish et al. 1995).

Recall that the Kalman filter enables us to track goodwill over time. These results suggest that the chain's goodwill increased during the period of our analysis. This is consistent with the significant positive effect of advertising as well as the increase in advertising expenditures during this period. To quantify the effect of this increase in goodwill, we simulated the sales that would have accrued in the third year (i.e., months 25-36) if goodwill had remained the same as in the first 12 months. The results suggest that growth in sales between years 1 and 3 would have been $15.08 \%$ as opposed to the $16.93 \%$ reported in Table 2. Therefore, the growth would have been lower by $10.95 \%$ in the absence of the evolution in

${ }^{20}$ Although we have presented the estimation section sequentially for ease of exposition, we estimate all the parameters simultaneously.
Table 4 Model Estimates

\begin{tabular}{lcrc}
\hline & Parameter & Estimate & Std. error \\
\hline Store-level & Price & -0.168 & 0.094 \\
$\quad$ parameters & Satisfaction & 0.516 & 0.255 \\
Chain-level & Carryover & 0.848 & 0.023 \\
$\quad$ parameters & Advertising & 0.320 & 0.025 \\
& Holiday & 0.113 & 0.015 \\
Census tract-level & Distance & -0.103 & 0.046 \\
$\quad$ parameters & & & \\
\hline
\end{tabular}

\section{Table 5 Descriptive Statistics of Store Fixed Effects}

\begin{tabular}{lr}
\hline Number of store fixed effects & 66 \\
Average & -4.845 \\
Standard deviation & 0.480 \\
Median & -4.762 \\
Maximum & -3.883 \\
Minimum & -6.026 \\
\hline
\end{tabular}

goodwill. ${ }^{21}$ This highlights the need to account for dynamics in our analysis.

In the estimation, we fix the travel cost to be positive by specifying the distance coefficient $\psi=$ $-\exp \left(\psi^{*}\right)$, where $\psi^{*}$ is the estimated parameter. ${ }^{22}$ The distance coefficient reported in Table 4 is -0.103 (standard error, 0.046). Hence, distance has a significant negative effect on the utility that consumers derive from a store belonging to the focal or the competing chain. In conjunction with the price coefficient, these results suggest a travel cost of approximately $\$ 0.60$ per mile. These results are close to the approximately $\$ 0.31$ per mile reported by Davis (2006) for movie theaters but significantly lower than the $\$ 3.00$ reported by Thomadsen (2005) for fast food. Some potential reasons for the difference between our estimate of travel cost and those reported by Thomadsen (2005) are worth highlighting. First, Thomadsen (2005) observed a much higher crosssectional variation in prices than those in our market. For example, Thomadsen (2005) reported price ranges of $\$ 1.10$ and $\$ 0.50$ for the signature sandwiches offered by McDonald's and Burger King, respectively. ${ }^{23}$ These are much higher than the crosssectional variation in our data (see, Figure 1). Because high travel cost implies that stores can act as local monopolists, his estimate appears to be consistent with the price variation that he observed. Second, Thomadsen (2005) did not observe sales. Therefore, he

\footnotetext{
${ }^{21}$ The rest of the growth can be attributed to other factors such as increase in the overall market size, opening of new stores, and the change in the composition of stores in favor of FSUs.

${ }^{22}$ Note that a negative distance coefficient is consistent with a positive travel cost.

${ }^{23}$ Data are reported in Table 1 of Thomadsen (2005).
} 
infered travel cost solely based on the cross-sectional variation in prices vis-à-vis spatial dispersion of outlets. In contrast, our inference of travel cost relies on how temporal variation in prices, satisfaction scores, and the entry/exit of competing stores affect the sales of outlets in different locations. It would be reasonable to argue that the variation in sales (cross-sectional and/or temporal) strengthens the case for the identification of travel cost. Third, unlike Thomadsen (2005), the panel nature of our data enables us to control for location endogeneity. As discussed earlier, not accounting for location endogeneity is likely to lead to overestimation of travel costs.

At the beginning of this paper, we had posed three research questions of managerial relevance: (a) What fraction of a store's sales constitutes incremental sales as opposed to drawing current customers of the chain from nearby stores? (b) How adverse would this cannibalization effect be for the nearby stores (i.e., what fraction of their sales do stores lose because of the existence of another store in its vicinity)? And (c) what growth in chain sales would leave the sales at incumbent stores unaffected by entry? Below, we answer these questions via policy simulations.

\subsection{Decomposing Sales}

To decompose the total sales generated by a store into incremental sales and cannibalization from nearby stores, we performed a policy simulation wherein we computed the chain-level sales that would accrue in the absence of each store. The difference between the actual chain-level sales and these simulated sales would be indicative of the incremental sales generated by each store after accounting for cannibalization. Similarly, the difference between the current sales of each store and the corresponding incremental sales would provide a measure of the extent to which the void created by closing the store would be filled by the other stores belonging to the chain. This is also the extent to which each store is currently competing with other stores belonging to the chain for the same set of customers. Based on this analysis, we find that, on average (across stores), 13.3\% of a store's sales would be picked up by other stores belonging to the chain if it were to shut down; approximately $86.7 \%$ of sales generated by each store are incremental. Furthermore, the results suggest significant heterogeneity across stores, with the percentage of their incremental sales ranging from $82.5 \%$ to $94.8 \%$. Note that this decomposition is conditional on the current geographical configuration of stores. Therefore, the results cannot be generalized beyond the current context. Nevertheless, the framework can be utilized to conduct similar decomposition analyses in other empirical contexts.

\subsubsection{Effect of New Store Openings on Chain-} Level Sales. We now seek to understand how the new stores opened by the chain during the period of our analysis contributed to its overall performance. To this end, we considered the three new stores (hereafter referred to as stores 26,45 , and 46 ), which were opened during the second year and therefore provided one full year of sales data for the chain both before and after their opening. This would help us smooth out any seasonal fluctuations. We present the results from this analysis in Table 6 . The results reveal that stores 26,45 , and 46 , on average, produced incremental sales of 64,907 units, 34,556 units, and 58,322 units per month, respectively. Therefore, stores 26 and 46 generated more incremental sales than an average store in the chain $(138 \%$ and $124 \%$ of average store sales, respectively). ${ }^{24}$ On the other hand, store 45 yielded incremental sales equivalent to only $74 \%$ of that of an average store. Based on this rough analysis, we can infer that opening of stores 26 and 46 might have increased the average sales per store.

The above analysis raises an interesting question as to why stores 26 and 46 were effective in generating incremental sales, whereas store 45 was not. Broadly, there are two reasons why store 45 might have been less effective in generating incremental sales: (a) lower ability to bring in new sales ${ }^{25}$ and/or (b) greater cannibalization from nearby stores. To disentangle the two effects, we report how the total sales generated by these stores can be decomposed into incremental sales versus cannibalization from nearby stores in Table 7. The results reveal that stores 26 and 46 would have generated significantly more incremental sales than store 45 . On the other hand, the cannibalization effects are of roughly the same magnitude for all three stores. This is not surprising because all three stores have roughly the same number of competing stores in their proximity (stores 26, 45, and 46 have one, two, and two competing stores within a two-mile radius, respectively). Therefore, stores 26 and 46 were more effective in bringing in new sales than store 45 .

Why are stores 26 and 46 more effective in generating higher incremental sales? There are some key observed characteristics on which Store 26 differs from the other two stores. First, store 26 has a highway exit within 0.6 miles, whereas stores 45 and 46 do not. It can be conjectured that stores located closer to highways have greater demand potential compared to stores that are not. Second, store 26 is located in

\footnotetext{
${ }^{24}$ We computed the average store sales by dividing the total chain sales in a period by the number of stores in the chain during that period. The average store sales during this period were 47,450 units per month.

${ }^{25}$ Note that these new sales might be due to new customers and/or more frequent visits by existing customers. Our data do not permit us to separate these two sources.
} 
Table 6 Additional Sales Generated by New Store

\begin{tabular}{lcccc}
\hline Average monthly chain & $\begin{array}{c}\text { Average monthly chain } \\
\text { sales with } \\
\text { store without }\end{array}$ & $\begin{array}{c}\text { Incremental sales } \\
\text { generated by } \\
\text { store }\end{array}$ & $\begin{array}{c}\text { Incremental sales as \% } \\
\text { of average monthly } \\
\text { sales per store (\%) }\end{array}$ \\
\hline 26 & $2,900,698$ & $2,965,605$ & 64,907 & 138 \\
45 & $2,931,049$ & $2,965,605$ & 34,556 & 74 \\
46 & $2,907,283$ & $2,965,605$ & 58,322 & 124 \\
\hline
\end{tabular}

Table 7 Chain-Level Cannibalization Effect of the New Store

\begin{tabular}{lcccc}
\hline Store & $\begin{array}{c}\text { Average incremental } \\
\text { monthly sales without } \\
\text { cannibalization }\end{array}$ & $\begin{array}{c}\text { Average net incremental } \\
\text { monthly sales after } \\
\text { accounting for cannibalization }\end{array}$ & $\begin{array}{c}\text { Chainwide } \\
\text { cannibalization } \\
\text { effect (units) }\end{array}$ & $\begin{array}{c}\text { Incremental } \\
\text { sales (\%) }\end{array}$ \\
\hline 26 & 68,425 & 64,907 & 3,518 & 95 \\
45 & 39,174 & 34,556 & 4,618 & 88 \\
46 & 65,111 & 58,322 & 6,789 & 90 \\
\hline
\end{tabular}

a much more densely populated area than the other two stores. However, stores 45 and 46 are located very close to each other and do not differ significantly in terms of observed local market characteristics. Therefore, the ability of store 46 to generate higher incremental sales is likely to be due to characteristics that are not observed by the researcher. This highlights the need to account for unobserved store characteristics using store fixed effects.

The results in Table 7 also suggest that the incremental sales generated by the stores as a percentage of their respective sales range from a low of $88 \%$ for store 45 to a high of $95 \%$ for store 26 . Based on our earlier analysis for all the stores belonging to the chain, we can say that the figures for stores 45 and 46 are close to the chain average of $86.7 \%$, whereas store 26 would fall at the higher end of the range in terms of this metric.

\subsection{Cannibalization at Individual Stores}

To understand the extent to which each store cannibalizes sales from the other stores in the neighborhood, we performed a policy simulation wherein we computed the sales of all the stores when the focal store is absent. We then compared this with the sales of the other stores when the focal store is present. The difference between the two would be indicative of the extent to which the new store cannibalizes sales. As discussed earlier, the presence of travel cost would imply a decaying cannibalization rate with distance. Nevertheless, two pairs of equidistant stores might experience different cannibalization rates based on store characteristics, local demographics, and competitive environment. ${ }^{26}$ Therefore, we present the distribution of cannibalization rates for different distance

\footnotetext{
${ }^{26}$ Note that these are the sales lost by individual incumbent expressed as a percentage of its average monthly sales. In contrast, the cannibalization estimates in $\$ 6.1$ are expressed as a percentage of the new store's sales. Therefore, one needs to be careful while comparing the cannibalization percentages in $\$ \S 6.1$ and 6.2.
}

bands in Figure 4. The results reveal that, on average, the cannibalization rate at a distance of one mile or less is approximately $1 \%$. The average cannibalization rate drops to less than $0.5 \%$ at a distance of $7-10$ miles. Moreover, the results in Figure 4 suggest significant variation in the cannibalization rates within each distance band. This variation is especially more pronounced at shorter distances. For example, at a distance of one mile, the cannibalization rate can vary from as low as $0.1 \%$ to as high as $2 \%$. As discussed above, this variation might be induced by a host of local characteristics.

To get a general picture regarding the rate at which cannibalization decays with distance, we estimated a model with the log of sales lost by store $j$ due to store $k$, i.e., $\ln \left(\Delta Q_{j k}\right)$, as the dependent variable and fixed effects for the store losing sales (i.e., store $j$ ) and the distance between the stores, $d_{j k}$, as independent variables. The store fixed effects control for the fact that stores with a larger sales base are likely to experience greater sales losses. The chosen functional form reflects the pattern of cannibalization reported in Figure 4 . The results suggest that, on average, when the distance between stores increases by one mile, the sales lost due to cannibalization decrease by $28.1 \%$. The inclusion of fixed effects in this analysis implies that different stores would experience different losses in sales due to a store opening at the same distance from them. This is despite the assumption that the

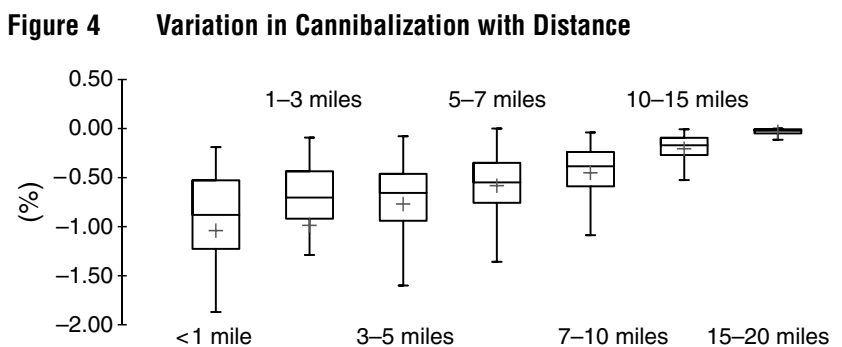


Table 8 Cannibalization Effect of the New Store on Nearby Stores

\begin{tabular}{lccccc}
\hline & \multicolumn{2}{c}{ Average store-level cannibalization (units) } & & \multicolumn{2}{c}{ Cannibalization as a \% of average store sales } \\
\cline { 2 - 3 } \cline { 5 - 6 } New store & $\begin{array}{c}\text { Stores within 10 miles } \\
\text { of the new store }\end{array}$ & $\begin{array}{c}\text { Stores }>10 \text { miles } \\
\text { from the new store }\end{array}$ & & $\begin{array}{c}\text { Stores within 10 miles } \\
\text { of the new store (\%) }\end{array}$ & $\begin{array}{c}\text { Stores }>10 \text { miles } \\
\text { from the new store (\%) }\end{array}$ \\
\hline Store 26 & 385 & 73 & & 1.23 & 0.16 \\
Store 45 & 467 & 52 & & 0.85 & 0.13 \\
Store 46 & 767 & 91 & & 1.61 & 0.22 \\
\hline
\end{tabular}

Figure 5 Cannibalization Curves for Four Stores

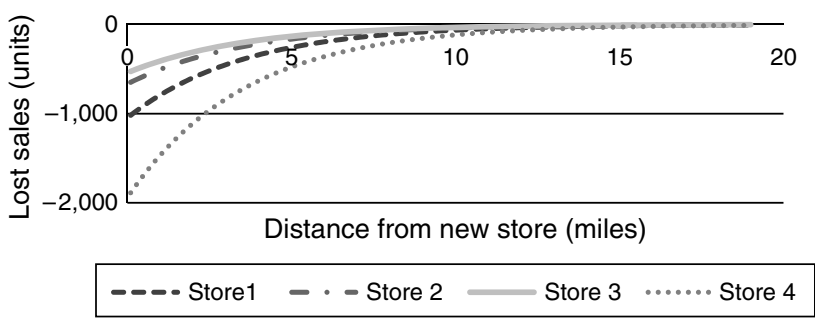

rate at which this loss decreases (in percentage terms) with distance is assumed to be the same across stores. We illustrate this for four stores in Figure 5. A comparison of Figures 4 and 5 suggests that our smooth characterization of the rate at which the adverse cannibalization effect decays with distance is similar to the observed pattern. ${ }^{27}$

6.2.1. Cannibalization Effect of New Store Openings on Nearby Stores. To understand the effect of new store openings on the sales of stores nearby (both old and other new stores), we computed the average sales cannibalized from stores within 10 miles of the new store as well as for stores that are located between 10 and 20 miles from the new store. We present these results in Table 8. Furthermore, we plot the adverse effect due to cannibalization for each store as a percentage of its original sales against their distance from the new store in Figures $6-8 .^{28}$ These results reveal two things. First, the average cannibalization effect for stores located within 10 miles of the new store ranged from $0.85 \%$ (for store 45 ) to $1.61 \%$ (for store 46). Furthermore, if we consider stores located between 10 and 20 miles from each other, the cannibalization effect almost vanishes. We cannot rule out the possibility that these low cannibalization estimates are due to strategic location decisions by

${ }^{27}$ Although Figure 4 represents cannibalization in percentage terms, the pattern of decay was not very different when we used lost sales.

${ }^{28}$ Note that the analysis in Figures 6-8 refers to the cannibalization effect (lost sales) of the new stores 25, 45, and 46 on other stores located at various distances from them. This is slightly different from Figures 4 and 5, where we discuss the cannibalization experienced by a store due to a store located at various distances from them.
Figure 6 Store Sales Change vs. Distance from Store 26

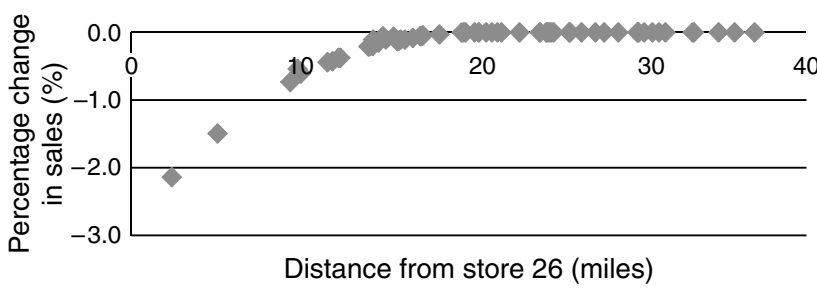

Figure 7 Store Sales Change vs. Distance from Store $\mathbf{4 5}$

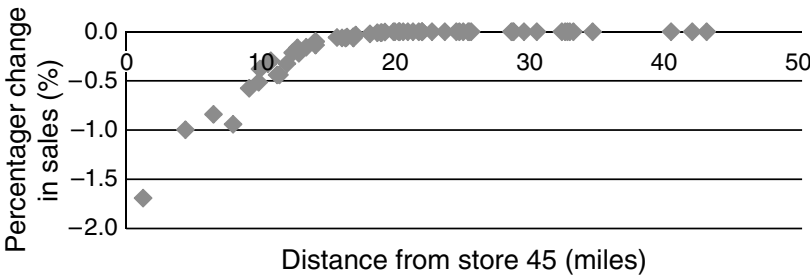

Figure 8 Store Sales Change vs. Distance from Store 46

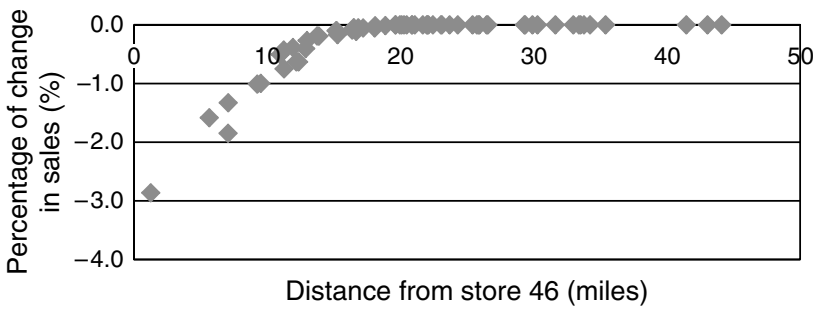

the firm. ${ }^{29}$ Second, the stores located within 10 miles of the new stores actually experienced growth in sales ranging from $0.4 \%$ to $6.4 \%$ between the first and the third years of the data. Clearly, this suggests that inferring cannibalization based on the observed change in sales after the new stores were opened would be inappropriate.

\subsection{New Store Openings in the Context of Franchises}

The two subsections above highlight the main source of conflict between franchisors and their franchisees.

${ }^{29}$ We would like to thank an anonymous reviewer for pointing this out. 
In instances where the franchisor receives a sales royalty from each franchisee, the former has incentive to open new outlets as long as the revenue from the new outlets exceeds the sales lost by those in its vicinity (Kaufmann and Rangan 1990, Kalnins 2003, Nair et al. 2009). On the other hand, if cannibalization effects are sufficiently high (i.e., because of low travel cost), incumbent franchisees are likely to complain about territorial encroachment. Whereas mechanisms to protect franchisees (such as territorial exclusivity or giving the closest franchisee a right to first refusal for ownership of the new outlet) have been considered (Kalnins 2003), we discuss an alternative approach to ward off any conflict between the two key stakeholders. Specifically, one can envision a scenario wherein the overall growth in the chain's goodwill can offset any loss in sales experienced by individual franchisees due to new store openings. In the spirit of Kaufmann and Rangan (1990), we can then use our model to infer the corresponding increase in advertising that would be required to achieve this increase in goodwill.

To this end, we performed the following policy simulation by keeping the goodwill during the last year (i.e., months 25-36) the same as in the first year (i.e., no growth due to increase in goodwill). Using this simulated goodwill, we computed (a) the sales that would accrue to the stores if each of the 66 stores was not present during the period of our analysis and (b) the corresponding figures with each store. The difference between (a) and (b) for each store (except the store that is being shut off) is a measure of the adverse effect that the store being shut off has on that store in the absence of any growth. Next, we identified the growth rate in sales between year 1 and year 3 that would generate the same sales in (b) as in (a) without growth. In essence, we are trying to determine the growth rate that would leave each franchisee indifferent between entry of another store and nonentry in the absence of growth (i.e., (a) above) ${ }^{30}$ Clearly, this "break-even" growth rate would depend on the distance between stores; stores closer to the new entrant would have a higher "break-even" growth rate.

We present the results from this analysis in Figure 9. The results reveal that, on average, stores located closer to the entrant have higher "break-even" growth rates. However, the differences in the configuration of stores and differences in the local market imply that there is significant variation in the break-even distance within each distance bucket. On average, for an entry at a distance of less than three miles, the franchisee needs to be assured of a $31.2 \%$ growth

\footnotetext{
${ }^{30}$ This assumes that each store is owned and operated by a different franchisee. Furthermore, it ignores the effect of entry on price competition.
}

Figure 9 Percentage Growth in Chain Sales Growth to Prevent Cannibalization

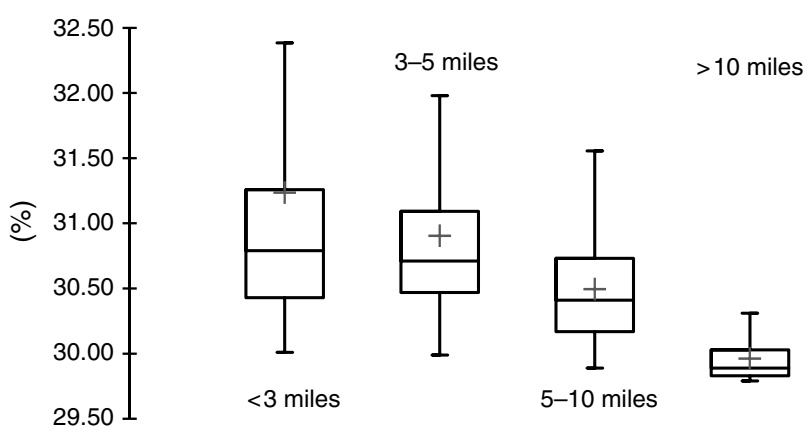

Figure 10 Percentage Increase in Ads Required to Prevent Cannibalization

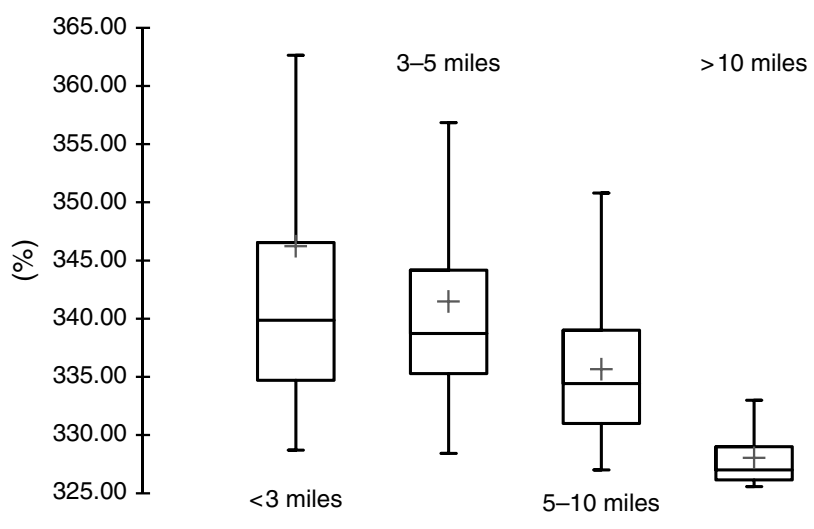

in overall chain sales between year 1 and year 3 . The franchisor can accomplish this by increasing the advertising outlay, for example. Based on the longterm advertising elasticities reported earlier, one can compute the corresponding increase in advertising that would be required to achieve this sales growth. We present these results in Figure 10. Based on this, we can infer that if an entry were to occur within three miles of an incumbent franchisee, the franchisor needs to increase the advertising budget by approximately $346 \%$ (on year 1 advertising levels) to leave the franchisee's sales unaffected. To put these figures in perspective, recall that the focal chain had increased its advertising budget by $79.55 \%$ and saw a $16.93 \%$ increase in same chain sales during this period (see Table 2). These results are consistent with the data pattern in Figure 3 wherein we observe that some incumbent stores located within close proximity of a new store actually experienced a decline in sales after entry.

\subsection{Managerial Implications}

The model presented in this paper can be a useful tool for managerial decision making. Specifically, 
Figure 11 Lost Sales due to Closure of Each Store

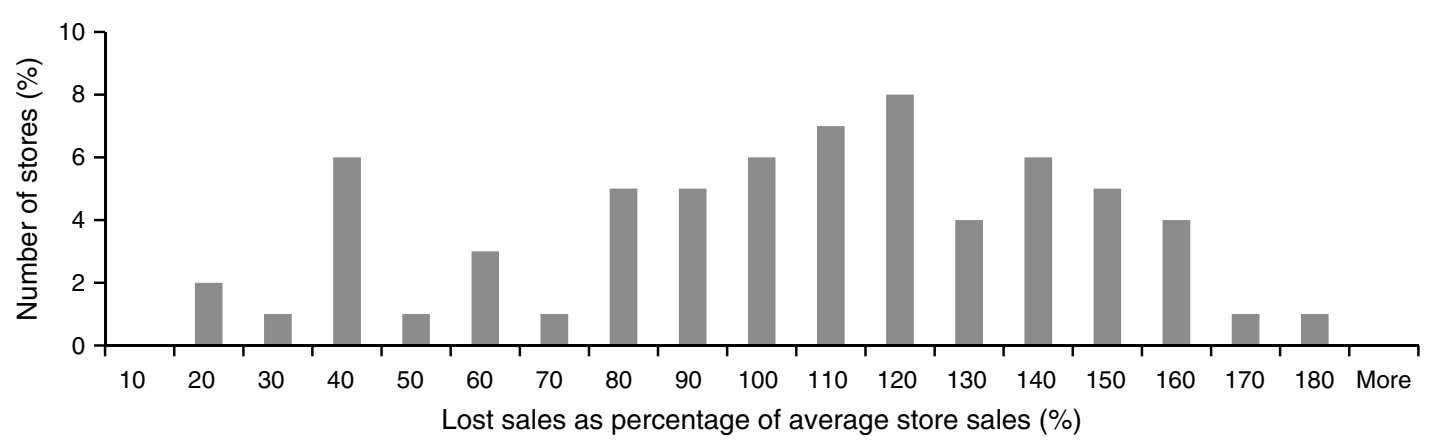

managers who are trying to downsize their retail presence can use the model to infer the marginal effect (at the chain level) of closing each store. The recent exercise by GM and Chrysler to identify dealerships that can be closed down (Kiley 2009) illustrates the managerial relevance of such an application. Although managers tend to use average sales to identify low-performing stores that can be closed down, such a heuristic is likely to present an incomplete picture. This is because average sales do not reflect the extent to which stores nearby would fill in the void created by the closure of a store. To illustrate this point, consider two stores $A$ and $B$, which have the same average sales. Furthermore, whereas store A has many other stores belonging to the chain in its vicinity, store $B$ does not. Under such a scenario, the chain would lose fewer sales due to the closure of store A because it has many other stores that can fill in the void created by its closure. Therefore, one needs to consider the spatial competition between retailers while identifying stores that can be closed down with the lowest marginal loss in sales. ${ }^{31}$ To illustrate this application, we present the incremental sales generated by each store (i.e., the sales that would be lost due to their closure) in Figure 11. These results suggest that the lost sales at the chain level due to closure of a store (expressed as a percentage of average store sales) would range between $14 \%$ and $163 \%$. To put this in perspective, recall that the corresponding figures from Table 6 for stores 45 and 46 were $74 \%$ and $124 \%$, respectively. The above analysis can also be performed to assess the impact of closing down multiple stores simultaneously. ${ }^{32}$

\footnotetext{
${ }^{31}$ This issue will be more pertinent in instances where there is a high degree of cannibalization due to the presence of a high concentration of stores belonging to a chain.

${ }^{32}$ The related issue of identifying the best among various alternative locations for opening a store is also possible. However, this would require us to predict the fixed effect for each potential location. To accomplish that, we would need to project the estimated fixed effects on store characteristics (such as store formats), local demographics, and competitive environment. We can then back out a predicted fixed effect for the new store.
}

\section{Conclusions}

In this paper, we propose a parsimonious demand model that captures spatial competition between retail outlets in a dynamic environment. The model also accounts for location endogeneity due to unobserved demand drivers. We demonstrate how the model can be used to infer (a) the incremental sales (after accounting for cannibalization) generated by the addition of a store (or the loss in sales due to store closure), (b) the adverse cannibalization effect of opening a new store on nearby stores as a function of the distance between them, and (c) break-even growth rates for overall chain sales to offset cannibalization for individual franchisees. The empirical application of this model takes advantage of a rich store-level panel data set on sales and price, consumer attitudinal data (satisfaction data) at the store level, as well as competitive entry and exit data at the market (census tract) level. We also discuss how the model can be used to make informed managerial decisions regarding store openings (or closures).

Although this paper provides an approach for addressing an important problem facing managers, it suffers from a few limitations that can provide avenues for future research. First, the data used in this application belong to one chain of fast food restaurants. Although the model can be readily extended to accommodate data from multiple chains, the empirical application suffers from this limitation. Using data from several chains might provide richer insights regarding the profit impact of opening new stores. Second, the changing composition of stores over time suggests that one can extend the analysis to jointly consider the location and timing of new store openings. In this regard, it would be interesting to incorporate the conflicting objectives of the franchisor and individual franchisees. Furthermore, the model can also be extended to capture location decisions wherein location choice might also be motivated by the objective of preempting a competing chain from opening a store nearby.

In sum, this paper seeks to make both methodological and substantive contributions to the extant 
literature on competition between geographically proximate outlets. We anticipate that future research will benefit and hopefully build on the approach presented in this paper.

\section{Acknowledgments}

The authors thank Pradeep Chintagunta, Fred Feinberg, Jeremy Fox, Hongju Liu, Puneet Manchanda, Harikesh Nair, Raj Venkatesan, Ting Zhu, participants at the 2009 Marketing Science Institute Young Scholars event and the 2009 and 2011 Marketing Science Conferences, and the seminar participants at the University of Massachusetts and the University of Michigan for their comments and suggestions. They also acknowledge the able research assistance of Sixing Chen, Shan Lin, Debra Piquette, Vikash Sharma, and Shuai Yang. The second author thanks 3M Corporation for financial support. They thank the anonymous firm for providing the data in this study, and Renu for copyediting this manuscript.

\section{References}

Akcura TM, Gonul F, Petrova E (2004) Consumer learning and brand valuation: An application on over-the-counter (OTC) Drugs. Marketing Sci. 23(4):156-169.

Assmus G, Farley J, Lehmann D (1984) How advertising affects sales: A meta-analysis of econometric results. J. Marketing Res. 21(1):65-74.

Bell DR, Ho T-H, Tang CS (1998) Determining where to shop: Fixed and variable costs of shopping. J. Marketing Res. 35(3):352-69.

Berry ST (1992) Estimation of a model of entry in the airline industry. Econometrica 60(4) 889-917.

Berry S, Levinsohn J, Pakes A (1995) Automobile prices in market equilibrium. Econometrica 63(4):841-890.

Bresnahan TF, Reiss PC (1991) Entry and competition in concentrated markets. J. Political Econom. 99(5):977-1009.

Craig CS, Ghosh A, McLafferty S (1984) Models of the retail location process: A review. J. Retailing 60(1):5-36.

Datta S, Sudhir K, Talukdar D (2008) A structural model of entry and location choice: The differentiation-agglomeration tradeoff. Working Paper, Yale School of Management, New Haven, CT.

Davis P (2006) Spatial competition in retail markets: Movie theaters. RAND J. Econom. 37(4):964-982.

Desai P, Srinivasan K (1995) Demand signalling under unobservable effort in franchising: Linear and nonlinear price contracts. Management Sci. 41(10):1608-1623.

Draganska M, Jain DC (2004) A likelihood approach to estimating market equilibrium models. Management Sci. 50(5):605-616.

Dube JP, Hitsch G, Manchanda P (2005) An empirical model of advertising dynamics. Quant. Marketing Econom. 3(2):107-144.

Evans WN, Froeb LM, Werden GJ (1993) Endogeneity in the concentration-price relationship: Causes, consequences and cures. J. Indust. Econom. 41(4):431-438.

Fotheringham AS (1991) Statistical modeling of spatial choice: An overview. Res. Marketing 5(Supplement 5):95-117.

Ghosh A, Craig CS (1986) An approach to determining optimal locations for new services. J. Marketing Res. 23(4):354-362.

Huff D (1964) Defining and estimating a Trading Area. J. Marketing 28(July):34-38.

Huff DL, Batsell RR (1977) Delimiting the areal extent of a market area. J. Marketing Res. 14(4):581-585.
Jedidi K, Mela CF, Gupta S (1999) Managing advertising and promotion for long-run profitability. Marketing Sci. 18(1):1-22.

Kalnins A (2003) Hamburger prices and spatial econometrics J. Econom. Management Strategy 12(4):591-616.

Kalnins A (2004) An empirical analysis of territorial encroachment within franchised and company-owned branded chains. Marketing Sci. 23(4):476-489.

Kaufmann PJ, Rangan VK (1990) A model for managing system conflict during franchise expansion. J. Retailing 66(2):155-173.

Kiley D (2009) Car dealers are fighting the hammer as chrysler and GM send out pink slips to retailers. Bus. Week (May 13).

Kiviat B (2008) Starbucks goes from venti to grande. Time (July 2).

Kumar V, Leone RP (1988) Measuring the effect of retail store promotions on brand and store substitution. J. Marketing Res. 25(2):178-185.

Lodish LM, Livelsberger J, Lubetkin B, Richardson B, Stevens ME (1995) A summary of fifty-five in-market experimental estimates of the long-term effects of TV advertising. Marketing Sci. 14(3):G133-G140.

Manuszak M, Moul C (2008) Prices and endogenous market structure in office supply superstores. J. Indust. Econom. 56(1):94-112.

Naik PA, Mantrala MK, Sawyer AG (1998) Planning media schedules in the presence of dynamic advertising quality. Marketing Sci. 17(3)214-235.

Naik PA, Raman K, Winer R (2005) Planning marketing-mix strategies in the presence of interaction effects. Marketing Sci. 24(1):25-34.

Nair S, Tikoo S, Liu S (2009) Valuing exclusivity from encroachment in franchising. J. Retailing 85(2):206-210.

Neelamegham R, Chintagunta P (2004) Modeling and forecasting of sales in technology products. Quant. Marketing Econom. 2(3):195-232.

Nevo A (2001) Measuring market power in the ready-to-eat cereal industry. Econometrica 69(2):307-342.

Putsis WP Jr (1998) Parameter variation and new product diffusion. J. Forecasting 17(3-4):231-257.

Quelch J (2008) Starbucks' lessons for premium brands. HBS Working Knowledge (July 9), http://hbswk.hbs.edu/item/5973.html.

Reilly W (1931) The Law of Retail Gravitation (Putnam, New York).

Rust RT, Donthu N (1995) Capturing geographically localized misspecification error in retail choice models J. Marketing Res. 32(1):103-110.

Seim K (2006) An empirical model of firm entry with endogenous product-type choices. RAND J. Econom. 37(3):619-640.

Singh V, Zhu $\mathrm{T}$ (2008) Pricing and market concentration in oligopoly markets. Marketing Sci. 27(6):1020-1035.

Sriram S, Kalwani M (2007) Optimal advertising and promotion budgets in dynamic markets with brand equity as a mediating variable. Management Sci. 53(1):46-60.

Sriram S, Chintagunta P, Neelamegham R (2006) Effects of brand preference, product attributes, and marketing mix variables in technology product markets. Marketing Sci. 25(5):440-456.

Sudhir K, Chintagunta PK, Kadiyali V (2005) Time-varying competition. Marketing Sci. 24(1):96-109.

Thomadsen $\mathrm{R}$ (2005) The effect of ownership structure on prices in geographically differentiated industries. RAND J. Econom. 36(4):908-929.

van Heerde H, Mela C, Manchanda P (2004) The dynamic effect of innovation on market structure. J. Marketing Res. 41(2):166-183.

Xie J, Song XM, Sirbu M, Wang Q (1997) Kalman filter estimation of new product diffusion models. J. Marketing Res. 35(3):378-393. 